\title{
Impressões, traduções: o pathos em Marcel Proust
}

\author{
Ronaldo Monte*
}

recebido: $05 / 2014$

aprovado: 07/2014

\begin{abstract}
Resumo: Enquanto Carpeaux identifica o estilo proustiano como "simbolismo mágico", outros autores preferem classificá-lo como "impressionista", numa correlação com o movimento contemporâneo das artes plásticas. Esta última classificação é mais útil aos propósitos deste trabalho que pretende encontrar as semelhanças do método proustiano com alguns aspectos da teoria psicanalitica.
\end{abstract}

Palavras-chave: Impressionismo, Simbolismo, Estilo proustiano, Método proustiano.

Abstract: While Carpeaux identifies the proustian style as "magical symbolism", other authors prefer to classify it as "impressionist", in correlation with the contemporary movement of the arts. The latter classification is more useful to the purposes of this work we intend to find the similarities of Proustian method with some aspects of psychoanalytic theory.

Keywords: Impressionism, Symbolism, Proustian style, Proustian method, psychoanalysis.

Enquanto Carpeaux identifica o estilo proustiano como "simbolismo mágico", outros autores preferem classificá-lo como "impressionista", numa correlação com o movimento contemporâneo das artes plásticas. Esta última classificação é mais útil aos propósitos deste trabalho que pretende encontrar as semelhanças do método com alguns aspectos da teoria psicanalítica.

“O escritor não precisa inventar, mas traduzir, porque o único livro verdadeiro é aquele que existe em cada um de nós. O dever e a tarefa de um escritor são os de um tradutor." M. Proust.

Na metade final de $O$ tempo redescoberto, sétima parte

* Professor aposentado do Departamento de Psicologia da UFPB. 
do romance Em busca do tempo perdido, Proust reflete sobre a essência da obra de arte, particularmente sobre sua própria obra. É um momento em que o autor revela todo o seu gênio literário, pois, subvertendo a linearidade do tempo, nos mostra como deveria ser escrita a obra que estava acabando de escrever.

Quem possui alguma familiaridade com o Projeto para uma psicologia científica, esboçado por Freud em 1895, sabe que este movimento retroativo é característico da constituição do traumatismo psíquico, em que são necessárias duas cenas separadas no tempo. Uma primeira cena, em que acontece um atentado sexual, se daria num período em que ainda não existia uma sexualidade na criança (período que Freud nomeia, curiosamente, de sexual-pré-sexual). Só depois, com a ocorrência de uma segunda cena, aparentemente anódina, mas com relações simbólicas com a primeira, o trauma se instalaria efetivamente.

Este movimento a posteriori pode ser considerado a chave para a compreensão de todo o romance proustiano, como muito bem o ilustra as quatro experiências tomadas pelo autor para demonstrar o seu processo de criação: a famosa experiência com a madeleine, as pedras irregulares do calçamento na entrada da casa dos Guermantes, as lembranças de um martelo batendo numa roda de trem causadas pelo barulho de uma colher batendo num prato e o delírio imediato causado pelo contato de um guardanapo em sua boca.

O modo fortuito e inevitável que, segundo o autor, surgiram essas sensações era uma "prova da verdade do passado que ressuscitava, das imagens que desencadeava, pois percebemos seu esforço para aflorar à luz, sentimos a alegria do real recapturado" (p. 130). Assim, um livro subjetivo seria

composto por esses sinais desconhecidos (sinais em
relevo, dir-se-ia, que minha atenção, explorando o
inconsciente, procurava, roçava, contornava como um
mergulhador em suas sondagens), ninguém me poderia,
com regra alguma, facilitar a leitura, consistindo esta
num ato criador que não admite suplentes nem
colaboradores.(p. 130).

Está toda presente aqui a noção proustiana da obra de arte como trabalho de tradução. Trabalho solitário em que nossos olhos viciados podem vislumbrar a atenção flutuante do 
artista roçando os contornos do inconsciente, tal como um contemporâneo seu já anunciava desde o limiar do século XX. Damos a Marcel Proust a prioridade de introduzir a questão da tradução, pois em "O tempo redescoberto" ele afirma que

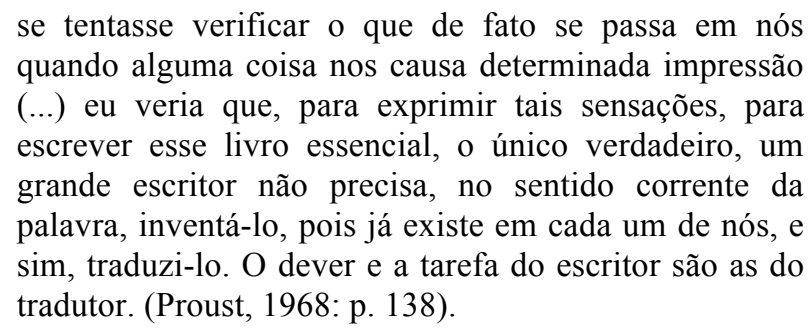
quando alguma coisa nos causa determinada impressão (...) eu veria que, para exprimir tais sensações, para escrever esse livro essencial, o único verdadeiro, um grande escritor não precisa, no sentido corrente da palavra, inventá-lo, pois já existe em cada um de nós, e sim, traduzi-lo. O dever e a tarefa do escritor são as do tradutor. (Proust, 1968: p. 138).

Provavelmente foi esta concepção do trabalho do escritor como tradutor levou Walter Benjamin a escrever, em 1921, A tarefa do tradutor, texto enigmático em que nos deparamos com a noção de teor, aquilo que na tradução é impossível de ser traduzido. Por mais que a tradução extraia o máximo do que for comunicável no original, nele permanece algo intocável, sendo, por isso mesmo, o que atrai e orienta o trabalho do verdadeiro tradutor. Atrevo-me a afirmar que este teor, na obra de Proust, é o próprio tempo; esse tempo perdido que o autor pretende ter redescoberto.

\section{O modelo tradutivo de Freud}

A noção de tradução está presente desde cedo no texto freudiano, tendo um papel primordial para a compreensão dos seus primeiros modelos do aparelho psíquico. No início da inesgotável Carta 52, endereçada a Fliess em 6 de dezembro de 1896, Freud informa que está trabalhando com a hipótese de que o aparelho psíquico se constitui por um processo de estratificação em que os traços de memória se submeteriam, periodicamente, a uma retranscrição, de acordo com novas circunstâncias. Essas transcrições sucessivas representariam a operação psíquica de épocas sucessivas da vida, na fronteira das quais necessariamente se efetuaria a tradução do material psíquico, de acordo com as características dos neurônios que dariam suporte a estas transcrições. Este aparelho tradutor baseia-se na tendência à nivelação quantitativa, sendo cada reescritura necessária para adequar a excitação às características

Problemata: R. Intern. Fil. v. 5. n. 1 (2014), p. 122-129 ISSN 2236-8612 
da via neuronal que lhe facilitará o trânsito na parte do trajeto de uma determinada jurisdição.

Ao percorrer um determinado caminho, uma certa excitação recebe uma significação diferente, de acordo com as características de cada trecho do percurso entre a percepção e a consciência. A cada nova transcrição, existe a possibilidade de permanecerem sem tradução determinadas partes do texto da versão anterior, por conta do desprazer que tal tradução geraria. Tais relíquias restariam anacrônicas no discurso atual de um determinado período, sendo, além do mais, passadas para o período posterior em sua forma arcaica não traduzida, onde causariam maior estranheza. Esta sucessão de traduções seria uma tentativa permanente do aparelho psíquico em se livrar de um excesso de excitação gerado pelos traços de percepção (Wahrnehmungszeichen) que desde a porta de entrada vem exigindo a impossível tarefa de sua tradução. E o desprazer causado pela ineficiência de cada tradução proposta provocará o ataque e dissolução desta organização provisória, permanecendo a exigência de uma reestruturação dos signos, da qual surgirão novos sentidos.

\section{Proust e a psicanálise}

Será que Marcel Proust, adepto das idéias de Bergson, conhecia a teoria desenvolvida pelo seu contemporâneo Sigmund Freud para nela se inspirar na sua concepção de tradução das impressões escondidas no íntimo do escritor?

Em sua História da literatura ocidental, Oto Maria Carpeaux afirma que tanto Proust quanto Joyce usaram a "psicologia em profundidade" para "destruir a arquitetura tradicional do romance" (p. 2409). Mas enquanto James Joyce (1882 - 1941) é considerado pela crítica como um discípulo de Freud, Marcel Proust (1871 - 1922) adere a outra vertente da psicologia profunda, o associacionismo, baseada em elementos do romantismo e do pré-simbolismo. E para isto serve-se das doutrinas e sugestões de Bergson, principalmente quando seu estilo abandona por completo a "ordem cronológica, substituindo-se o 'temps fixé' dos relógios pela 'durée mobile' da memória bergsoniana; daí a composição da obra, constituída de certo número de grandes blocos, dos quais cada um é 
iluminado por um 'flash de insight'." (p.2416).

Ainda segundo Carpeaux, Proust "não chegou às interpretações psicanalíticas", embora seu estilo acentue, mais do que esconda, uma confusão intencional, mimetizando a confusão própria dos sonhos.

\begin{abstract}
"Apenas, os sonhos de Proust não foram realmente sonhados. São sonhos artificiais (sem sentido pejorativo) sonhos deliberadamente imaginados, e neste ponto - na transformação imediata do sonho em obra de arte - é Proust realmente um psicólogo 'moderníssimo'. Todos os personagens de À La recherche du temps perdu são projeções da alma do artista Proust que sonha; e, como sempre acontece no sonho, aparecem entre os desejos e receios personificados os 'resíduos do dia anterior', quer dizer, restos memorados do único mundo real que o pobre doente conhecera nos 'anos anteriores'. Eis o mundo mundano de Marcel Proust.” (p. 2416).
\end{abstract}

Para acentuar mais ainda essa distância de Proust e a teoria psicanalítica, Carpeaux o separa de Joyce para aproximálo de outro contemporâneo seu, Ítalo Svevo (1861 - 1929). Em seu obra prima, A consciência de Zeno, Svevo mostra as "motivações inconscientes da personagem central, Zeno Cosini, e disseca toda a sua vida familiar e sexual. Expondo os processos interiores da consciência, Svevo desnuda o ambiente convencional da burguesia italiana" (A consciência de Zeno, Posfácio, p. 382).

O que nos impressiona é a possibilidade de que um autor informado como Proust tenha ficado à margem da influência psicanalítica. É ainda Carpeaux que afirma ser Freud mais "contemporâneo de Proust que de Joyce; a sua Interpretação dos sonhos é de 1900. Quando Proust, por volta de 1920, se tornou famoso, já se notou nele o pouco conhecimento da psicanálise. Quer dizer: Proust é homem da época na qual a nova psicologia apenas estava 'no ar'; ele respirava essa atmosfera." (Carpeaux, 2010: p. 2411).

Enquanto Carpeaux identifica o estilo proustiano como "simbolismo mágico", outros autores preferem classificá-lo como "impressionista", numa correlação com o movimento contemporâneo das artes plásticas. Esta última classificação é mais útil aos propósitos deste trabalho que pretende encontrar as semelhanças do método proustiano com alguns aspectos da 
teoria psicanalítica. A impressão, nos diz Proust, “é para o escritor o mesmo que a experimentação para o sábio, com a diferença de ser neste anterior e naquele posterior o trabalho da inteligência." (Proust, 1958: p. 130).

\section{Impressões, transferência}

Dentre as muitas digressões sobre o seu método de criação, Proust nos fala, em $O$ tempo redescoberto, sobre a necessidade da "análise em profundidade das impressões, depois de recriadas pela memória" (Proust, 1958: p.242). Ora, ele nos pergunta, "a recriação, pela memória, das impressões que depois seria mister aprofundar, esclarecer, transformar em equivalentes intelectuais, não seria uma das condições, quase a própria essência da obra de arte...?" (Idem: p. 249).

Pensamento semelhante é expresso por Freud já na Interpretação dos sonhos (1900), quando afirma que o sistema Perceptivo, que "supre a nossa consciência com toda a multiplicidade das qualidades sensoriais" não possui memória. É necessário que essas qualidades sensoriais sejam transferidas para um sistema de memória posterior ao sistema perceptivo. Essas lembranças gravadas em nossas mentes, mesmo as mais profundas, prossegue Freud, "são, em si próprias, inconscientes". Essas lembranças podem, eventualmente, se tornar conscientes. Mas mesmo que permaneçam numa condição inconsciente, podem produzir em nós todos os seus efeitos. Nossa constituição psíquica está baseada nos traços de memória de nossas impressões. Além disso, afirma Freud, "as impressões que causaram o maior efeito em nós, as de nossa primeira infância, são precisamente aquelas que dificilmente se tornam conscientes". Mesmo que estas lembranças, esses traços de memória resultado das impressões, venham "mais uma vez" a se tornar conscientes, não exibirão sua qualidade sensória ou, então, "apenas uma qualidade muito leve, em confronto com as percepções". Mesmo que Freud não o afirme aqui, essas qualidades sensórias somente podem ser relembradas a partir da reprodução no processo transferencial das impressões que delas se originaram.

Trabalho semelhante ao da recriação transferencial pode ser encontrado em Proust. É o trabalho do artista, em que ele 
busca sob a matéria, sob a experiência e sob as palavras, algo diferente daquilo que o amor próprio, a paixão, a inteligência e o hábito fazem a todo instante, quando estamos alheios a nós mesmos. Para o autor,

esta arte tão complicada é justamente a única viva. Só ela exprime para os outros e a nós mesmos mostra a nossa própria vida, essa vida que não pode ser 'observada', cujas aparências observáveis precisam ser traduzidas, frequentemente lidas às avessas, e a custo decifradas." (Proust, 1958, p. 142).

É nesse campo transferencial formado entre o artista e sua obra que o autor se submete à exigência compulsiva que não nos deixa livres "diante da obra de arte, que não a fazemos como queremos, mas que, sendo preexistente, compete-nos, porque é necessária e oculta e porque o faríamos se se tratasse de uma lei da natureza, descobri-la.” (P. 131).

É nesse campo transferencial que vêm se atualizar todos os elementos depositados no interior do artista como traços de percepção.

\section{Pathos e tradução}

Tanto Freud quanto Proust estão empenhados em decifrar estes traços de percepção. Mas ainda não sabemos se tais impressões pertencem já à ordem dos signos, ou se seu estatuto é meramente psicológico, ainda do lado de fora do circuito pulsional. Para obtermos uma resposta, permaneçamos ainda na Carta 52, onde a clínica mostra que os sintomas das psiconeuroses, tais como ataques de vertigem e acessos de choro, têm como alvo uma outra pessoa. Mas não uma pessoa comum. É um outro pré-histórico, inesquecível, uma pessoa "que nunca é igualada por nenhuma outra posterior" (Freud, 1895 [1968] p. 239). E o exemplo dado logo em seguida nos indica esse outro: a mãe.

Se na sucessão de gerações é necessário um perverso para gerar um histérico, não é o pai, mas a mãe que Freud coloca no lugar desse outro pré-histórico, inesquecível, inigualável. Inigualável, porque não vai ser nunca substituído; inesquecível, mas apenas em um dos lugares do aparelho psíquico. E o seu 
inesquecimento, a sua eterna permanência deve-se exatamente ao seu caráter sexual pré-histórico. Um sexual pré-sexual, pois pertence à ordem pulsional do outro, implantando a sexualidade pelo seu caráter mesmo de intraduzível. É anterior à palavra, apresentando-se a um infans sem capital significante para nomeá-lo.

Precisamos recorrer a George Painter, o mais exaustivo biógrafo de Proust para encontrar esta mãe a quem a eterna criança diz, velando-a no seu leito de morte: "não poderei viver sem você", ouvindo de volta a promessa impossível: "Não tenha medo, filhinho, sua mãe não o abandonará.”

E será a freira que acompanhou os últimos momentos de vida dessa mãe onipresente que dirá a Proust, num misto de admiração e censura: "Para sua mãe você ainda era um menino de quatro anos."

E foi para reconstruir esta figura ambígua que Proust escreveu o seu romance-rio. Para que as suas águas lentas e caudalosas limpassem sua alma desse pathos materno que nunca deixou de lhe fazer uma exigência de tradução.

\section{Bibliografia}

BENJAMIN, W. A tarefa do tradutor. Cadernos do Mestrado, Rio de Janeiro, Programa de Pós Graduação em Letras da UFRJ. 1994.

. Die Aufgabe dês Übersetzers. Gesammelt Schifren, Frankfurt am main: Suhrkamp, 1991.

CARPEUX, O. M. História da literatura universal. Brasília; Senado federal, Conselho Editorial, 2010.

FREUD, S. Extracts from the Fliess papers (1895). In: _. The Standard Edition of the Complete Works of Sigmund Freud. London: Hogarth Press, 1968.

. A interpretação dos sonhos (1900). In . Edição Standard

brasileira das obras psicológicas completas de Sigmund Freud. Rio de Janeiro: Imago Editora, 1972.

PAINTER, G. D. Marcel Proust. Rio de janeiro: Editora Guanabara Koogan, 1990.

PROUST, M. O tempo redescoberto. In Em busca do tempo perdido. Porto Alegre: Editora Globo, 1958. 